\title{
Self-reported arm and shoulder problems in breast cancer survivors in Sub-Saharan Africa: the African Breast Cancer-Disparities in Outcomes cohort study
}

Pauline Boucheron ${ }^{1 *} \mathbb{D}$, Angelica Anele ${ }^{2}$, Annelle Zietsman ${ }^{3}$, Moses Galukande ${ }^{4}$, Groesbeck Parham ${ }^{5}$, Leeya F. Pinder ${ }^{6}$, Therese M.-L. Andersson, Benjamin O. Anderson ${ }^{6,8}$, Milena Foerster ${ }^{1}$, Joachim Schüz ${ }^{1}$ (D), Isabel dos Santos Silva ${ }^{9}$ and Valerie McCormack ${ }^{1}$ (D)

\begin{abstract}
Background: Arm and shoulder problems (ASP), including lymphedema, were common among women with breast cancer in high-income countries before sentinel lymph node biopsy became the standard of care. Although ASP impair quality of life, as they affect daily life activities, their frequency and determinants in Sub-Saharan Africa remain unclear.

Methods: All women newly diagnosed with breast cancer at the Namibian, Ugandan, Nigerian, and Zambian sites of the African Breast Cancer-Disparities in Outcomes (ABC-DO) cohort study were included. At each 3-month followup interview, women answered the EORTC-QLQ-Br23 questionnaire, including three ASP items: shoulder/arm pain, arm stiffness, and arm/hand swelling. We estimated the cumulative incidence of first self-reported ASP, overall and stratified by study and treatment status, with deaths treated as competing events. To identify determinants of ASP, we estimated cause-specific hazard ratios using Cox models stratified by study site.
\end{abstract}

Results: Among 1476 women, up to 4 years after diagnosis, 43\% (95\% Cl 40-46), 36\% (33-38) and 23\% (20-25), respectively, self-reported having experienced arm/shoulder pain, stiffness and arm/hand swelling at least once. Although risks of self-reported ASP differed between sites, a more advanced breast cancer stage at diagnosis, having a lower socioeconomic position and receiving treatment increased the risk of reporting an ASP.

Conclusion: ASP are very common in breast cancer survivors in Sub-Saharan Africa. They are influenced by different factors than those observed in high-income countries. There is a need to raise awareness and improve management of ASP within the African setting.

Keywords: Arm and shoulder problems, Lymphedema, Lymphoedema, Lymphodema, Sub-Saharan Africa, Breast cancer, Low- and middle-income countries, Arm swelling, Arm stiffness, Shoulder pain

*Correspondence: boucheronp@fellows.iarc.fr

${ }^{1}$ International Agency for Research On Cancer (IARC/WHO), Environment and Lifestyle Epidemiology Branch, Lyon, France

Full list of author information is available at the end of the article

\section{Background}

Breast cancer is the most commonly diagnosed cancer in women worldwide [1]. In 2020, 129,000 Sub-Saharan African women were newly diagnosed with this cancer, and the incidence is projected to increase [1]. Before the development of sentinel lymph node biopsy, in original author(s) and the source, provide a link to the Creative Commons licence, and indicate if changes were made. The images or other third party material in this article are included in the article's Creative Commons licence, unless indicated otherwise in a credit line to the material. If material is not included in the article's Creative Commons licence and your intended use is not permitted by statutory regulation or exceeds the permitted use, you will need to obtain permission directly from the copyright holder. To view a copy of this licence, visit http://creativecommons.org/licenses/by/4.0/. The Creative Commons Public Domain Dedication waiver (http://creativeco mmons.org/publicdomain/zero/1.0/) applies to the data made available in this article, unless otherwise stated in a credit line to the data. 
high-income countries (HICs), arm and shoulder problems (ASP), defined by stiffness, pain and swelling, were frequent among breast cancer patients and survivors. In this context, ASP were typically ipsilateral and occurred due to axillary lymph node dissection, mastectomy, chemotherapy, and radiotherapy. ASP risk factors also included number of lymph nodes removed, older age, and high body mass index (BMI) [2-4]. Although ASP are not life threatening, they impair women's quality of life in the long-term as they affect daily life and activities [5].

In Sub-Saharan Africa (SSA), the frequency of ASP in breast cancer survivors is unclear. A recent metaanalysis that aimed to assess the prevalence and incidence of lymphedema (i.e. arm swelling) in low- and middle-income countries (LMICs), which included only one study from SSA, could not obtain a pooled estimate because of large between-study heterogeneity [6]. This was due to the differences in study designs, in measurement methods and definitions, and duration of followup. Since this meta-analysis, a few additional studies from SSA have been published but none was designed to estimate the frequency of ASP, and they were too small to allow a thorough investigation of ASP risk factors [4, 7-10].

Risk factors for ASP in SSA may differ from that of HICs because of the very advanced stage at breast cancer diagnosis, different treatment courses or the broader environment including the physical burden in daily life or infectious agents [11-13]. In this setting, a substantial proportion of women do not receive timely, complete or high-quality treatment [14]. For instance, surgical procedures commonly used in HICs, such as sentinel lymph node biopsy and breast-conserving surgery, are less often performed in SSA where mastectomy and axillary lymph node dissection are the predominant surgical procedures. Moreover, ASP can already be present at the time of diagnosis, before treatment initiation, due to the physical impact of extremely large tumour sizes and high number of affected lymph nodes at diagnosis. Furthermore, it is conceivable that risk factors may vary across different ethnic groups.

In this context, the present study aimed to estimate the frequency and determinants of ASP after a breast cancer diagnosis within the African Breast Cancer-Disparities in Outcomes (ABC-DO) cohort, a prospective cohort of women with breast cancer in five SSA countries.

\section{Methods}

\section{Study design and data collection}

This study was part of the African Breast Cancer-Disparities in Outcomes (ABC-DO) study, a prospective multicentric hospital-based cohort study of disparities in survival in women after a diagnosis of breast cancer.
ABC-DO was conducted in Nigeria, Zambia, Uganda, Namibia and South Africa and its protocol is available elsewhere [15]. In brief, from September 2014 to early 2017, all women aged 18 and above who visited one of the participating hospitals and were suspected of having breast cancer were invited to participate. Of 2313 women recruited with suspected breast cancer, 2228 had the disease confirmed by histology, cytology or clinically. Overall, 2212 (99\%) of those eligible women accepted to participate and were included in ABC-DO.

\section{Data collection}

At baseline, data on women's sociodemographic characteristics, comorbidities, breast cancer risk factors and health attitudes, knowledge and beliefs were collected via an interviewer-administered questionnaire. The woman agreed to be contacted thereafter every three months by mobile phone. MHealth technology was used for all real-time data collection and to facilitate contact with women or their next of kin every three-months, using a standardized protocol that minimized losses to followup [16]. At each 3-month follow-up contact, data on treatment (surgery, radiotherapy, chemotherapy, and endocrine therapy) were collected from both medical records and self-reports. The woman also answered the EORTC-QLQ-Br23 questionnaire, an internationally validated questionnaire to assess quality of life of women with breast cancer [17]. For the primary ASP outcomes, we used responses to the three questions pertaining, at each trimonthly contact, to the past week "Did you have pain in your arm or shoulder?"; "Did you have a swollen arm or hand?" and "Was it difficult to raise your arm or to move it sideways?" for information on arm or shoulder pain, arm or hand swelling and arm stiffness, respectively. Each of the three items were rated on a four-point Likert scale of "not at all", "a little", "quite a bit" and "very much". In the present analysis, each ASP was considered present if rated "quite a bit" or "very much" and absent otherwise, as was previously done in other studies $[5,18,19]$.

\section{Inclusion criteria and exclusion criteria}

For the purpose of this analysis, all women enrolled into ABC-DO were included except those from South Africa $(n=675)$ because the regular follow-up at this site did not systematically ascertain ASP. Prevalent breast cancer cases (i.e. women with a previous diagnosis of breast cancer more than two years before enrolment $n=57$ ) or who were lost to follow-up immediately after diagnosis were also excluded $(n=4)$, leaving 1476 women in the analysis.

\section{Determinants of ASP}

Sociodemographic characteristics, tumour characteristics and type of treatment received, regardless of whether 
treatment was completed or not, were assessed in relation to each ASP self-reporting. These included: (1) Five population groups defined by country and ethnicity (Namibia black, Namibia non-black, Uganda, Nigeria and Zambia); (2) TNM stage at diagnosis (stage I/ II, III, IV and unknown); (3) age at diagnosis (continuous, $<50$ years and $\geq 50$ ); (4) highest educational level (none or primary school, secondary or high school, university or technical degree); (5) body mass index (BMI) calculated from measured height and weight at baseline (continuous and $<25 \mathrm{~kg} / \mathrm{m}^{2},\left[25-30\left[\mathrm{Kg} / \mathrm{m}^{2}, \geq 30 \mathrm{~kg} / \mathrm{m}^{2}\right.\right.$ ); (6) self-reported HIV status at baseline (positive, negative or unknown); (7) Self-reported hypertension (yes, no) at baseline based on the question "Have you ever been diagnosed with hypertension?"; (8) treatment and specific types of treatment (surgery, radiotherapy, chemotherapy, endocrine therapy) were considered as categorical timevarying variable, and we performed a Lexis expansion to take into account change in treatment status over time (prior treatment: yes/no/unknown) [20].

\section{Statistical analysis}

For each ASP, we examined time to the first report of the ASP. Follow-up started from the date of diagnosis and ended on the date of interview when the ASP was first reported, the date of death (as a competing event), the date when 4-year follow-up was reached, date of last live contact or 1st January 2020, whichever came first. Using this time scale, we calculated the cumulative incidence of each ASP, overall and stratified by study site, from time since diagnosis prior to receiving treatment.

To identify potential determinants for each ASP, we fitted Cox proportional hazards models. Crude models were fitted for all potential determinants adjusted for age as a continuous variable and stratified by study site. We used likelihood ratio tests to determine whether age, BMI, educational level and tumour stage would be better explained as continuous or categorical. For each ASP, a multivariate model was fitted mutually adjusting for the same set of covariates (i.e. age, BMI, educational level, stage at diagnosis and treatment received). These models yielded adjusted cause-specific hazard ratios (CHR) estimates which shows the relative change in the rate of ASP according to each determinant, in women who are currently alive.

To assess the robustness of the findings we conducted further analysis to estimate: (1) cumulative incidence of the first self-reported ASP stratified by type of ASP and tumour stage at diagnosis; (2) cumulative incidence using a more strict definition of ASP based on time to the first report of a specific ASP in a 12-month period when there were multiple reports of that ASP (not necessarily consecutive); for the latter analyses, cumulative incidences are reported up to three years after diagnosis to allow for a subsequent multiple report within the following 12-months (maximal follow-up 4-years). In addition, we fitted the multivariate models described above but conditional on women having survived the first 6 months after diagnosis and excluding those with metastatic disease, as these women might not have received the same treatment as less advanced cases, and might have been at higher risk of reporting ASP. Lastly, to better understand the respective impacts of breast cancer itself and treatment on occurrence of ASP, we estimated one-year cumulative incidences of self-reported ASP prior to and after starting treatment. All analyses were performed using STATA v15.1.

\section{Results}

\section{Study population}

Of the 1476 women included in this analysis, there were 477 Namibian, 418 Ugandan, 383 Nigerian and 198 Zambian women. Table 1 presents baseline characteristics of these women. Briefly, mean age at diagnosis was 50.3 years $(\mathrm{SD}=13.7)$. About half of the women had none or primary school education level $(N=657$, $44.5 \%$ ), and most were diagnosed with late-stage breast cancer $(N=1106,75.0 \%)$. Concerning comorbidities, 342 (23.2\%) of women were obese, 144 (9.8\%) were HIV-positive and 426 (28.9\%) had hypertension. Although there were important between-country disparities in treatment received, overall, 171 women $(11.6 \%)$ did not receive any treatment, $928(62.9 \%)$ received chemotherapy, 841 (57.0\%) had surgery, 694 (47.0\%) endocrine therapy, and 465 (31.5\%) radiotherapy.

\section{Distribution of self-reported ASP}

Of the 1476 women included in this analysis, 162 (11.0\%) died before completing the first follow-up interview. Overall, 743 (50.3\%) of the 1476 women reported at least once an ASP, 618 (41.9\%) arm/shoulder pain, 516 (35.0\%) arm stiffness and 319 (21.6\%) arm/hand swelling (Fig. 1). Of the 238 (16.1\%) women who reported having experienced two different ASP, either concomitantly or at different follow-up time points, 187 (78.6\%) reported both arm/shoulder pain and arm stiffness, 33 (13.9\%) reported pain and arm/hand swelling, and 18 (7.6\%) reported both arm stiffness and swelling. Finally, 236 (16.0\%) women reported having experienced all three ASP.

\section{Cumulative incidence of self-reported ASP}

Four years after being diagnosed with breast cancer, cumulative incidences of shoulder/arm pain, stiffness and $\mathrm{arm} / \mathrm{hand}$ swelling were $43.0 \%$ (95\% CI 40.4-45.6), $35.8 \%$ (33.4-38.3) and 22.5\% (20.4-24.8), based on 618, 516 and 319 women, respectively (Table 2). Among the 
Table 1 Baseline characteristics of the newly diagnosed breast cancer patients enrolled in the ABC-DO cohort study

\begin{tabular}{|c|c|c|c|c|c|c|}
\hline & $\begin{array}{l}\text { Namibia Non- } \\
\text { Black }(N=97)\end{array}$ & $\begin{array}{l}\text { Namibia } \\
\text { Black } \\
(N=380)\end{array}$ & Uganda $(N=418)$ & Nigeria $(N=383)$ & Zambia $(N=198)$ & Overall $(N=1476)$ \\
\hline & $N(\%)$ & $N(\%)$ & $N(\%)$ & $N(\%)$ & $N(\%)$ & $N(\%)$ \\
\hline Mean age at diagnosis, years (SD) & $56.7(12.5)$ & $52.6(15.0)$ & $48.4(12.7)$ & $48.7(12.3)$ & $50.0(14.8)$ & $50.3(13.7)$ \\
\hline \multicolumn{7}{|c|}{$B M l, \mathrm{~kg} / \mathrm{m}^{2}$} \\
\hline$<25$ & $31(32.0)$ & $162(42.6)$ & $201(48.1)$ & $162(42.3)$ & $81(40.9)$ & $637(43.2)$ \\
\hline$[25-30[$ & $20(20.6)$ & $98(25.8)$ & $148(35.4)$ & $107(27.9)$ & $53(26.8)$ & $426(28.9)$ \\
\hline $30+$ & $41(42.3)$ & $102(26.8)$ & $60(14.4)$ & $94(24.5)$ & $45(22.7)$ & $342(23.2)$ \\
\hline Unknown & $5(5.2)$ & $18(4.7)$ & $9(2.2)$ & $20(5.2)$ & $19(9.6)$ & $71(4.8)$ \\
\hline \multicolumn{7}{|l|}{ Education } \\
\hline None/primary & $13(13.4)$ & $197(51.8)$ & $242(57.9)$ & $102(26.6)$ & $103(52.0)$ & $657(44.5)$ \\
\hline Secondary/high school & $46(47.4)$ & $132(34.7)$ & $126(30.1)$ & $144(37.6)$ & $54(27.3)$ & $502(34.0)$ \\
\hline Technical/university & $38(39.2)$ & $51(13.4)$ & $50(12.0)$ & $137(35.8)$ & $41(20.7)$ & $317(21.5)$ \\
\hline \multicolumn{7}{|l|}{ HIV status } \\
\hline Positive & $3(3.1)$ & $53(13.9)$ & $48(11.5)$ & $9(2.3)$ & $31(15.7)$ & $144(9.8)$ \\
\hline \multicolumn{7}{|l|}{ Hypertension } \\
\hline Yes & $49(50.5)$ & $155(40.8)$ & $65(15.6)$ & $100(26.1)$ & $57(28.8)$ & $426(28.9)$ \\
\hline \multicolumn{7}{|l|}{ Tumour stage at diagnosis } \\
\hline Localized (stage TNM I/II) & $48(49.5)$ & $73(19.2)$ & $96(23.0)$ & $39(10.2)$ & $19(9.6)$ & $275(18.6)$ \\
\hline Locally advanced (stage TNM III) & $43(44.3)$ & $247(65.0)$ & $226(54.1)$ & $256(66.8)$ & $131(66.2)$ & $903(61.2)$ \\
\hline Metastatic (stage TNM IV) & $6(6.2)$ & $60(15.8)$ & $64(15.3)$ & $60(15.7)$ & $13(6.6)$ & $203(13.8)$ \\
\hline Unknown & $0(0.0)$ & $0(0.0)$ & $32(7.7)$ & $28(7.3)$ & $35(17.7)$ & $95(6.4)$ \\
\hline \multicolumn{7}{|l|}{ Treated } \\
\hline No & $0(0.0)$ & $1(0.3)$ & $36(8.6)$ & $95(24.8)$ & $39(19.7)$ & $171(11.6)$ \\
\hline Yes & $97(100.0)$ & 376 (98.9) & 359 (85.9) & $262(68.4)$ & $140(70.7)$ & 1234 (83.6) \\
\hline Unknown & $0(0.0)$ & $3(0.8)$ & $23(5.5)$ & $26(6.8)$ & $19(9.6)$ & $71(4.8)$ \\
\hline \multicolumn{7}{|l|}{ Surgery ${ }^{a}$} \\
\hline No & $9(9.3)$ & $88(23.2)$ & $125(29.9)$ & $150(39.2)$ & 85 (42.9) & $457(31.0)$ \\
\hline Yes & 84 (86.6) & $244(64.2)$ & $240(57.4)$ & $183(47.8)$ & $90(45.5)$ & $841(57.0)$ \\
\hline Unknown & $4(4.1)$ & $48(12.6)$ & $53(12.7)$ & $50(13.1)$ & $23(11.6)$ & $178(12.1)$ \\
\hline \multicolumn{7}{|l|}{ Radiotherapy } \\
\hline No & $24(24.7)$ & $72(18.9)$ & $276(66.0)$ & $308(80.4)$ & $130(65.7)$ & $810(54.9)$ \\
\hline Yes & $71(73.2)$ & $287(75.5)$ & $56(13.4)$ & $11(2.9)$ & $40(20.2)$ & $465(31.5)$ \\
\hline Unknown & $0(0.0)$ & $0(0.0)$ & $0(0.0)$ & $0(0.0)$ & $0(0.0)$ & $0(0.0)$ \\
\hline \multicolumn{7}{|l|}{ Endocrine therapy } \\
\hline No & 18 (18.6) & $76(20.0)$ & $194(46.4)$ & $210(54.8)$ & $109(55.1)$ & $607(41.1)$ \\
\hline Yes & 76 (78.4) & 276 (72.6) & $151(36.1)$ & $127(33.2)$ & $64(32.3)$ & $694(47.0)$ \\
\hline Unknown & $0(0.0)$ & $0(0.0)$ & $0(0.0)$ & $0(0.0)$ & $0(0.0)$ & $0(0.0)$ \\
\hline \multicolumn{7}{|l|}{ Chemotherapy } \\
\hline No & $26(26.8)$ & 64 (16.8) & $74(17.7)$ & $164(42.8)$ & $55(27.8)$ & $383(25.9)$ \\
\hline Yes & $70(72.2)$ & $290(76.3)$ & $283(67.7)$ & $170(44.4)$ & $115(58.1)$ & $928(62.9)$ \\
\hline Unknown & $1(1.0)$ & $26(6.8)$ & $61(14.6)$ & 49 (12.8) & $28(14.1)$ & 165 (11.2) \\
\hline
\end{tabular}

${ }^{\mathrm{a}}$ In ABC-DO, surgeries were mostly mastectomies (82\%) as compared to lumpectomies. These were, respectively, 80\%, 92\%, 91\%, 50\% and 94\% in Namibian NonBlack, Namibian Black, Ugandan, Nigerian, and Zambian women

171 untreated women, these cumulative incidences were, respectively, $29.2 \%(21.9-36.8), 21.2 \%(14.7-28.4)$ and $15.3 \%$ (9.8-21.9) based on 47, 33 and 23 women, respectively (Additional file 1: Table S1). In comparison to prior to receiving any treatment, cumulative incidences of
ASP were two to three times higher after treatment start (Additional file 2: Table S2 and Additional file 3: Fig. S1). About half of all women who reported a specific ASP had multiple reports of that ASP within a 12-months period (Additional file 4: Fig. S2). The rate at which new ASPs 


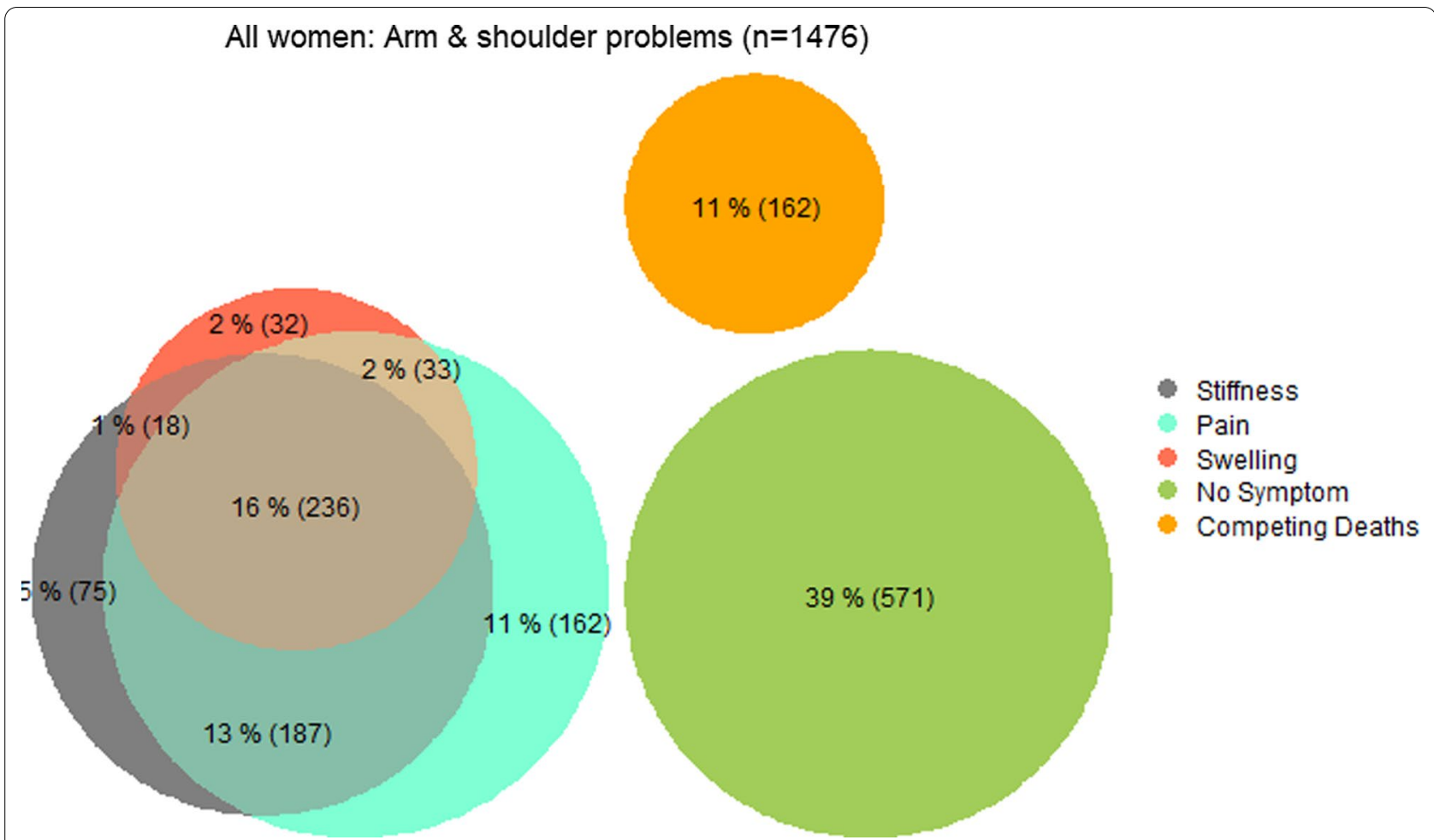

Fig. 1 Crude proportion $(n=1476)$ of women who self-reported at least once having experienced ASP, by type of ASP, in ABC-DO

Table 2 Four years post-diagnosis cumulative incidence of first self-reported ASP in ABCDO, by country and treatment

No. women with outcome/total (competing deaths)

$618 / 1476(449)$
$25 / 97(12)$
$151 / 380(100)$
$214 / 418(119)$
$162 / 383(141)$
$66 / 198(77)$

$516 / 1476(505)$

26/97 (13)

$148 / 380(106)$

$184 / 418(133)$

$106 / 383(176)$

$52 / 198(77)$

$319 / 1476(602)$

$13 / 97(16)$

$81 / 380(130)$

$103 / 418(180)$

$84 / 383(191)$

$38 / 198(85)$
Time at risk (person-years) ASP type-specific cumulative incidence at 4 years since diagnosis $(95 \% \mathrm{Cl})$

$43.0(40.4-45.6)$

$26.0(17.7-35.1)$

$40.3(35.3-45.2)$

$51.8(46.9-56.5)$

$44.0(38.7-49.3)$

$35.1(28.3-42.0)$

35.8 (33.4-38.3)

$26.9(18.5-36.0)$

$39.3(34.3-44.2)$

$44.7(39.8-49.5)$

$28.8(24.2-33.6)$

$27.9(21.6-34.5)$

$22.5(20.4-24.8)$

$13.7(7.7-21.4)$

$21.9(17.8-26.3)$

$25.1(21.0-29.4)$

$23.3(19.0-28.0)$

$20.4(15.0-26.5)$ 
were reported declined over time, with half of the 4-year cumulative reporting incidence occurring within the first year of diagnosis (Additional file 4: Fig. S2).

\section{Determinants of first self-reported ASP}

Determinants of first self-reported ASP, separately for each ASP type, are described in detail in Table 3, and in Additional file 5: Table S3 and Additional file 6: Fig. S3. After adjusting on all potential determinants of ASP identified in crude analysis, there were important between-country and between-ethnicity disparities. Relative to Namibia black women, the risk of a first ASP selfreport was lowest for non-black Namibians for all three ASP and highest for Ugandan women for all ASP (fully adjusted CHR 2.00; 95\%CI 1.61-2.48 for shoulder/arm pain, 1.52 (1.21-1.90) for arm stiffness and 1.59 (1.182.15) for arm/hand swelling), and for Nigerian women for all ASP except arm stiffness.

Tumour stage at diagnosis was the main determinant of ASP self-reporting (Table 3 and Additional file 7: Fig. S4), with women diagnosed with a more advanced stage tumour having an increased risk of self-reporting an ASP ( $p$ for heterogeneity $<0.0001$ for all three types of ASP). The strongest association was observed for arm swelling - relative to women with localized disease at diagnosis, the risk of self-reporting this ASP was two times higher (CHR 1.98; 95\% CI 1.40-2.79) for women with locally advanced cancers, and four times higher $(4.02 ; 2.59-6.23)$ for those with metastatic disease.

The risk of self-reporting an ASP was inversely associated with the woman's educational level for all ASP (Table 3), being particularly marked for shoulder/arm pain and arm stiffness ( $p$ for trend $<0.0001$ ). Relative to women with a university level, those with only primary school level or less were 94\% (fully adjusted CHR 1.94; 95\% CI 1.51-2.49) more likely to self-report shoulder/ arm pain and $77 \%(1.77 ; 1.34-2.33)$ more likely to selfreport arm stiffness. Older age at breast cancer diagnosis ( $\geq 50$ years) tended to be associated with a higher reporting of shoulder/arm pain (CHR 1.18; 95\% CI 0.99-1.39, $p=0.06$ ), but there was no evidence that the risk of selfreporting any of the three ASPs depended on a woman's BMI, HIV status or hypertension.

Receiving treatment was associated with the likelihood of reporting shoulder/arm pain (CHR 1.37; 95\% CI 1.08-1.72) and arm/hand swelling (CHR 1.67; 95\% CI 1.16-2.41). These associations were driven by chemotherapy, which increased the risk of reporting an ASP by about $50 \%$ for both shoulder/arm pain (CHR 1.48; 95\% CI 1.21-1.82) and arm stiffness (1.48; 1.17-1.87), and by up to $65 \%$ for arm/hand swelling $(1.65 ; 1.22-2.23)$. In contrast, surgery decreased the risk of reporting a shoulder/arm pain by about $25 \%(0.76 ; 0.63-0.92)$. However, when stratifying the analysis according to tumour stage at diagnosis, these treatment effects were only observed in women with late stage cancers (Additional file 8: Table S4).

After excluding women with metastatic cancer and conditioning the analysis on 6-month survival, results remained similar. However, receiving radiotherapy reduced the risk of reporting an arm stiffness, and this association was strongest in women diagnosed with a localized breast cancer (Additional file 8: Table S4).

\section{Discussion}

\section{Main findings}

Using data from a large and multi-centric cohort, we obtained robust estimates of the frequency of ASP in women after a breast cancer diagnosis across multiple SSA settings and examined their determinants. To our knowledge, our study is the first in SSA to show that ASP occur not only after receiving treatment but may also be present prior to treatment. The frequency of self-reported ASP was high in this setting, but with important between-country disparities. Overall, about 1 out of 2 women reported having experienced a moderate to severe ASP at least once during the follow-up period. Shoulder/arm pain was the most commonly reported ASP, followed by arm stiffness and arm/hand swelling, and most often, women reported multiple ASP types either concomitantly or at different follow-up time points. Among women who reported having experienced ASP, about half reported the same type of ASP more than once over time. More advanced breast cancer stage at diagnosis, older age, having a lower socioeconomic position and receiving treatment increased the risk of selfreported ASP.

\section{ASP frequency in SSA}

Our estimates of ASP frequency in SSA were higher than those previously reported in the region, maybe due to differences in study designs, sample sizes, ASP assessment methods and follow-up durations $[4,9,10]$. There were, however, important between-country disparities in ASP reporting, with Namibian non-black women reporting ASP the least, and Ugandan women the most. These differences, which remained after controlling for the earlier stage at breast cancer diagnosis of non-Namibian black women, may reflect over- or under-reporting of ASP for cultural reasons, variations in data collection quality or in interpretation of EORTC-QLQ-Br23 questions across sites, and/or ethnic differences in a woman's susceptibility to develop an ASP, because within Namibia, non-black women tended to report less ASP than black women. Lifestyle and treatment management and aftercare will also differ substantially. 
Table 3 Fully adjusted associations of baseline sociodemographic, tumour and treatment characteristics with first self-reported ASP

\begin{tabular}{|c|c|c|c|c|c|c|c|c|c|}
\hline & \multicolumn{3}{|c|}{ No. women with outcome/total } & \multicolumn{6}{|c|}{ Fully adjusted CHR $(95 \% \mathrm{Cl})^{\mathrm{a}, \mathrm{b}}$} \\
\hline & $\begin{array}{l}\text { Shoulder/arm } \\
\text { pain }\end{array}$ & Arm stiffness & $\begin{array}{l}\text { Arm/hand } \\
\text { swelling }\end{array}$ & Shoulder/arm pe & & Arm stiffness & & Arm/hand swell & ling \\
\hline \multicolumn{10}{|l|}{$\begin{array}{l}\text { Study site, } \\
\text { ethnicity }\end{array}$} \\
\hline Namibia Black & $151 / 380$ & $148 / 380$ & $81 / 380$ & 1 & & 1 & & 1 & 0.001 \\
\hline $\begin{array}{l}\text { Namibia Non- } \\
\text { Black }\end{array}$ & 25/97 & 26/97 & 13/97 & $0.71(0.46-1.10)$ & $<0.0001$ & $0.78(0.50-1.20)$ & 0.0002 & $0.68(0.37-1.24)$ & \\
\hline Uganda & $214 / 418$ & $184 / 418$ & $103 / 418$ & $2.00(1.61-2.48)$ & & $1.52(1.21-1.90)$ & & $1.59(1.18-2.15)$ & \\
\hline Nigeria & $162 / 383$ & $106 / 383$ & $84 / 383$ & $1.88(1.48-2.39)$ & & $1.06(0.81-1.39)$ & & $1.69(1.21-2.34)$ & \\
\hline Zambia & $66 / 198$ & $52 / 198$ & $38 / 198$ & $1.19(0.88-1.61)$ & & $0.91(0.66-1.27)$ & & $1.35(0.90-2.03)$ & \\
\hline \multicolumn{10}{|l|}{$\begin{array}{l}\text { Age at diagnosis } \\
\text { (years) }\end{array}$} \\
\hline$<50$ & $307 / 780$ & $255 / 780$ & 157/780 & 1 & 0.06 & 1 & 0.23 & 1 & 0.10 \\
\hline$\geq 50$ & $311 / 696$ & $261 / 696$ & $162 / 696$ & $1.18(0.99-1.39)$ & & $1.12(0.93-1.35)$ & & $1.22(0.96-1.53)$ & \\
\hline $\begin{array}{l}\text { per } 10 \text { years } \\
\text { increase }\end{array}$ & $618 / 1476$ & $516 / 1476$ & $319 / 1476$ & $1.04(0.98-1.11)$ & 0.21 & $1.04(0.97-1.11)$ & 0.31 & $1.04(0.95-1.13)$ & 0.43 \\
\hline \multicolumn{10}{|l|}{$B M I\left(K g / \mathrm{m}^{2}\right)$} \\
\hline$<25$ & 273/637 & 229/637 & 129/637 & 1 & 0.37 & 1 & 0.30 & 1 & 0.41 \\
\hline [25-30[ & $176 / 426$ & $144 / 426$ & $95 / 426$ & $0.88(0.72-1.06)$ & & $0.89(0.72-1.09)$ & & $1.04(0.79-1.35)$ & \\
\hline $30+$ & $140 / 342$ & $120 / 342$ & $80 / 342$ & $0.99(0.80-1.21)$ & & $1.07(0.85-1.34)$ & & $1.21(0.91-1.60)$ & \\
\hline $\begin{array}{l}\text { per } 5 \mathrm{~kg} / \mathrm{m}^{2} \\
\text { increase }\end{array}$ & $618 / 1476$ & $516 / 1476$ & $319 / 1476$ & $1.00(0.93-1.07)$ & 0.94 & $1.03(0.96-1.12)$ & 0.40 & $1.11(1.01-1.22)$ & 0.03 \\
\hline \multicolumn{10}{|l|}{ Education } \\
\hline $\begin{array}{l}\text { University/ } \\
\text { technical }\end{array}$ & $106 / 317$ & $84 / 317$ & $66 / 317$ & 1 & & 1 & & 1 & 0.07 \\
\hline $\begin{array}{l}\text { Secondary/ } \\
\text { high school }\end{array}$ & 196/502 & $161 / 502$ & $95 / 502$ & $1.48(1.16-1.88)$ & & $1.41(1.08-1.84)$ & & $1.08(0.78-1.49)$ & \\
\hline $\begin{array}{l}\text { None/Primary } \\
\text { school }\end{array}$ & $316 / 657$ & $271 / 657$ & $158 / 657$ & $1.94(1.51-2.49)$ & & $1.77(1.34-2.33)$ & & $1.41(1.02-1.96)$ & \\
\hline $\begin{array}{l}\text { Per decrease } \\
\text { in educational } \\
\text { level }\end{array}$ & $618 / 1476$ & $516 / 1476$ & $319 / 1476$ & $1.38(1.22-1.56)$ & $<0.0001$ & $1.32(1.16-1.51)$ & $<0.0001$ & $1.20(1.02-1.41)$ & 0.03 \\
\hline \multicolumn{10}{|l|}{$\begin{array}{l}\text { HIV status at } \\
\text { breast cancer } \\
\text { diagnosis }\end{array}$} \\
\hline $\begin{array}{l}\text { Negative/ } \\
\text { Unknown }\end{array}$ & $562 / 1332$ & $460 / 1332$ & 291/1332 & 1 & 0.85 & 1 & 0.14 & 1 & $>0.99$ \\
\hline Positive & $56 / 144$ & $56 / 144$ & $28 / 144$ & $0.97(0.73-1.29)$ & & $1.24(0.93-1.65)$ & & $1.00(0.67-1.49)$ & \\
\hline \multicolumn{10}{|l|}{$\begin{array}{l}\text { Ever diagnosed } \\
\text { with hyperten- } \\
\text { sion }\end{array}$} \\
\hline No & $432 / 1050$ & $363 / 1050$ & $215 / 1050$ & 1 & 0.11 & 1 & 0.99 & 1 & 0.15 \\
\hline Yes & $186 / 426$ & $153 / 426$ & $104 / 426$ & $1.17(0.96-1.42)$ & & $1.00(0.81-1.23)$ & & $1.22(0.93-1.58)$ & \\
\hline \multicolumn{10}{|l|}{$\begin{array}{l}\text { Tumour stage at } \\
\text { diagnosis }\end{array}$} \\
\hline Localized & $91 / 275$ & $79 / 275$ & $40 / 275$ & 1 & $<0.0001$ & 1 & $<0.0001$ & 1 & $<0.0001$ \\
\hline $\begin{array}{l}\text { Locally } \\
\text { advanced }\end{array}$ & $413 / 903$ & $343 / 903$ & 207/903 & $1.70(1.35-2.14)$ & & $1.66(1.29-2.13)$ & & $1.98(1.40-2.79)$ & \\
\hline Metastatic & $79 / 203$ & $68 / 203$ & $48 / 203$ & $2.44(1.78-3.33)$ & & $2.69(1.92-3.77)$ & & $4.02(2.59-6.23)$ & \\
\hline \multicolumn{10}{|l|}{ Prior treatment } \\
\hline No & 105/237 & $75 / 221$ & $41 / 197$ & 1 & 0.01 & 1 & 0.08 & 1 & 0.01 \\
\hline Yes & $496 / 1168$ & $429 / 1184$ & 270/1208 & $1.37(1.08-1.72)$ & & $1.27(0.97-1.67)$ & & $1.67(1.16-2.41)$ & \\
\hline \multicolumn{10}{|l|}{ Prior surgery ${ }^{c}$} \\
\hline No & $248 / 512$ & 185/497 & $116 / 482$ & 1 & 0.01 & 1 & 0.21 & 1 & 0.19 \\
\hline
\end{tabular}


Table 3 (continued)

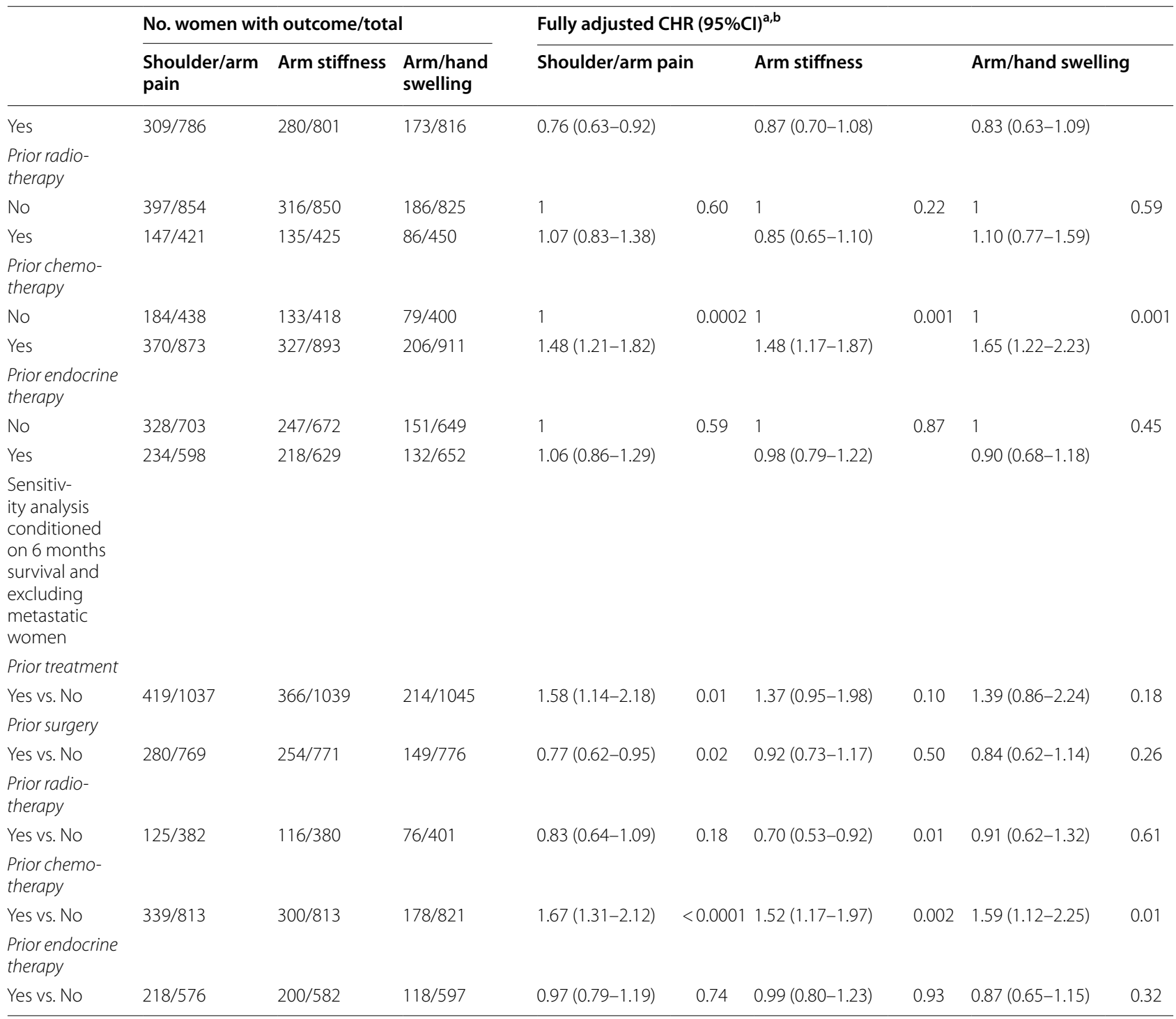

CHR cause-specific hazard ratio, $\mathrm{Cl}$ confidence interval

${ }^{\text {a }}$ For study site, age, BMI, education, tumour stage and prior treatment: fully adjusted CHRs are stratified on study site, and adjusted on age (continuous), BMI (categorical), education (continuous), tumour stage (categorical), and prior treatment

${ }^{b}$ For Prior surgery, prior radiotherapy, prior chemotherapy, Prior endocrine therapy: fully adjusted CHRs are stratified on study site, and adjusted on age (continuous), BMI (categorical), education (continuous), tumour stage (categorical), and mutually adjusted on each specific treatment type

${ }^{c}$ Of women who received a surgery and reported an arm/shoulder pain during the follow-up, $84 \%$ had a mastectomy. For arm stiffness and arm/hand swelling, these percentages were, respectively, $89 \%$ and $87 \%$

\section{Sociodemographic determinants of ASP}

In $A B C-D O$, women with lower educational level were at higher risk of self-reporting an ASP, irrespective of tumour stage at diagnosis, maybe due to lower breast cancer awareness and higher physical demands of their daily cores [11]. Women over 50 years of age tended to be at higher risk of self-reporting a shoulder/arm pain, which contrasts with the findings from a South African study in which the prevalence of ASP decreased with age
[4]. Also, we did not find an association between BMI and ASP, possibly because it was only measured once, at breast cancer diagnosis, and we were not able to capture its change over time in the analysis [21].

\section{Medical determinants of ASP}

In our study, a higher breast cancer stage at diagnosis was the most important determinant of self-reporting an ASP. In contrast to HICs where most women have 
an early stage diagnosis, late stage diagnosis for breast cancer is common in SSA due to low breast cancer awareness among both women and healthcare professionals, and long delays to presentation of symptomatic women to a healthcare provider, final diagnosis and treatment initiation, with disadvantaged populations being particularly affected [11, 12, 22, 23]. In our cohort, three quarters of women had a late stage breast cancer at diagnosis, with nearly half having a tumour size over five centimetres and about two thirds positive lymph nodes at diagnosis. It is plausible that, the larger tumours, and the increased number of affected lymph nodes in women with an advanced breast cancer, may have favoured ASP development, including prior to receiving treatment $[24,25]$.

Receiving treatment also increased the risk of reporting an ASP in women with advanced breast cancers, but our study may have lacked statistical power to detect an association in women with localized breast cancers. This association may partly be due to remaining unmeasured systematic differences between women who underwent specific treatment types and those who did not. The treatment effect was driven by chemotherapy, while surgery was associated with lower selfreporting of shoulder/arm pain, in line with what was found in another South African study with similar cohort characteristics [4]. Indeed, in our study, chemotherapy was the first treatment given and its initiation may have preceded the first follow-up interview. Women who received chemotherapy had higher SEP indicators and higher stage at diagnosis than women who did not. While chemotherapy is usually administered through central lines in HICs, these are not available in most LMICs where peripheral intravenous perfusions are used instead, as in our cohort. It is therefore possible that chemotherapy drugs administered through a peripheral line engender side-effects such as local inflammation and ASP. However, our study was not designed to assess treatment effects and thus we cannot exclude the possibility that the observed chemotherapy-ASP association may be due to local symptoms caused by the breast cancer itself $[26,27]$. Despite the more invasive surgical procedures often used in SSA, as compared to HICs, such as mastectomy and axillary lymph node dissection, it is possible that surgical removal of large tumours or a high number of affected lymph nodes relieve pain in women with advanced disease $[4,8,28,29]$. We also found that women diagnosed with an early stage cancer who survived at least six months had lower risk of self-reporting an ASP after receiving radiotherapy, which contrasts with previous studies results and needs to be further investigated [26].

\section{Strengths}

To our knowledge, this study is the first to provide estimates of ASP burden related to breast cancer in Zambia, Uganda, and Namibia. Major strengths of this study were its multi-country design and large sample size; the use of a common protocol and data collection system for all four study sites, and of mHealth technology for study management, data collection and active follow-up of the participants. With the exception of Zambia, where an interruption of follow-up led to irreversible losses to follow-up, mHealth has ensured very few losses to followup in ABC-DO, and timely death notification [16]. The use of the validated EORTC-QLQ-Br23 questionnaire, a quality-of-life questionnaire with a special module for breast cancer patients, allowed us to capture accurate, affordable, and reproducible measures of ASP experienced by women in our cohort. Our study demonstrated that this questionnaire can be used to monitor breast cancer survivors across different countries and ethnicities in SSA, similarly to what has been shown in HICs [17]. Our large study population and relatively high number of arm and shoulder outcomes enabled us to obtain reliable and accurate estimates of ASP burden, and to study their determinants in the Sub-Saharan setting.

\section{Limitations}

Our study population may not be representative of all breast cancer patients in SSA and the frequency of ASP. This is because recruitment was hospital-based, and some breast cancer cases may not seek care or may not be referred. However, hospital settings were tertiary centres, which is often the only treatment centre in the country and participation rate was very high (about 99\%). After the baseline interview, at each 3-month follow-up contact, women were asked to report whether they had experienced ASP in the previous week. At the time of the first EORTC-QLQ-Br23 questionnaire, some women had already experienced an ASP. Therefore, our estimates are a proxy for incidence of ASP in this population because the baseline rates of ASP could not be determined in our population and those that occurred in between the 3-month follow-up interviews may have been missed. Moreover, EORTC-QLQ-Br23 questions did not specify the side affected by ASP. In light of these considerations, we would advise future studies focussed on ASPs to (1) perform clinical measurements whenever possible; (2) ascertain a time-stamped history of ASPs at the time of diagnosis; (3) for each of the above, separately ascertain ASPs for the affected and contralateral breast and, in parallel, obtain laterality information for all treatments administered. As compared to objective measurement, patients' self-reports of arm swelling have been shown to have high sensitivity, but only moderate specificity [30], 
with the resulting false-positives leading to an over-estimation of the frequency of ASP. We improved specificity by only considering moderate to severe self-reported arm symptoms as indicative of ASP, as was done in other studies $[5,18,19]$. Moreover, the use of a validated questionnaire and standardized procedures to collect data on ASP limited the impact of misclassification on the study results. In our cohort, as the vast majority of women who received surgery got a mastectomy and data on axillary management was lacking, we were not able to analyse the impact of breast surgery type or axillary management technique on occurrence of ASP.

\section{Research implications}

This study highlights the high frequency of ASP following a breast cancer diagnosis in SSA as well as the presence of marked differences between countries and, in Namibia, also between ethnic groups. Indeed, the cost of breast cancer-related ASP is not only physical or emotional by lowering a woman's quality-of-life, but it may also have financial consequences, notably by impacting on a woman's ability to work, or by engendering higher medical needs and costs (e.g. in the case of repeated infections due to lymphedema) $[4,31-33]$. This may result in dramatic consequences on a woman's ability to get appropriate care and take care of her family. Thus, identifying modifiable risk factors of ASP that could be targeted by future interventions is crucial to help preventing ASP in SSA. Further research is needed to better understand the impact of treatment on the occurrence of ASP in this setting (e.g. studies with complete treatment data including quality of surgery and after care, chemotherapy administration mode and associated side-effects, studies comparing women's pain score pre- and post-surgery).

As WHO launches its Global Breast Cancer Initiative in 2021, improving the diagnosis, prevention, and management of ASP in LMICs is important. Breast cancer care and survivorship programmes need to be developed in SSA, and should combine educational, financial, and emotional support components to significantly improve breast cancer patient's quality-of-life and reduce the burden of ASP [25, 34-36]. These programmes should address ASP awareness, prevention, detection, and management. Moreover, they would need to reach breast cancer patients, health care professionals and also traditional healers, as these play an important role in cancer care delivery in this setting [37]. Affordable self-management measures should be emphasized and could be implemented in settings where access to care is lacking, and women should have access to physical and decongestive therapies whenever possible. Moreover, downstaging breast cancer is crucial to further reduce ASP burden in SSA, by raising awareness of this disease and by promoting its early detection in the region, especially among underprivileged populations who are the most at risk of late breast cancer diagnosis.

\section{Conclusion}

This study provides up-to-date estimates of ASP burden in women living with breast cancer in SSA and gives insights on their determinants. In this setting, women affected by breast cancer are at high risk of reporting an ASP that may significantly impair their quality-of-life and contribute to worsen social inequities. To reduce the burden of ASP, appropriate breast cancer downstaging strategies, as well as patient and survivorship care programmes that include long-term surveillance, are needed.

\section{Abbreviations}

ABC-DO: African Breast Cancer-Disparities in Outcomes; ASP: Arm and shoulder problems; BMI: Body Mass Index; CHR: Cause-specific Hazard ratio; Cl: Confidence interval; EORTC-QLQ-BR23: European Organisation for Research and Treatment of Cancer breast-cancer specific quality-of-life questionnaire module; IARC: International Agency for Research on Cancer; HIC: High-income countries; IQR: Interquartile range; LMIC: Low- and middle-income countries; SD: Standard deviation; SEP: Socioeconomic position; SSA: Sub-Saharan Africa; WHO: World Health Organisation.

\section{Supplementary Information}

The online version contains supplementary material available at https://doi. org/10.1186/s13058-021-01486-9.

Additional file 1: Table S1. Four years post-diagnosis cumulative incidence of first self-reported ASP in untreated women in ABC-DO.

Additional file 2: Table S2. One-year cumulative incidences of first selfreported ASP prior to and after starting treatment in ABC-DO.

Additional file 3: Fig. S1. Cumulative incidence curves of first selfreported ASP, prior to and after starting treatment in ABC-DO.

Additional file 4: Fig. S2. Cumulative incidence curve of first and multiple self-reported ASP, by country and ethnicity.

Additional file 5: Table S3. Crude associations of baseline sociodemographic, tumour and treatment characteristics with first self-reported ASP.

Additional file 6: Fig. S3. Forest plot of determinants of first self-reported ASP. This forest plot shows fully adjusted associations between baseline and tumour characteristics, and treatment types with first self-reports of each ASP.

Additional file 7: Fig. S4. Cumulative incidence curve of first selfreported ASP, by tumour stage.

Additional file 8: Table S4. Fully adjusted associations between treatment types and first self-reported ASP, by tumour stage.

\section{Acknowledgements}

This manuscript is dedicated to Charles Adisa, a PI of ABC-DO, who sadly passed away in December 2020. The authors thank the women who participated in this study. They also thank the dedicated team of research assistants, notably Johanna Pontac, Allen Naamala, Agnes Kaggwa, Anne Ntezir-yayo, Teopista Nakazibwe, Chris Sule Oyamienlen, Kingsley Iwuoha, Esther Ezeigbo, Mildred Lusaka, and Mirriam Mudolo.

\section{Disclaimer}

Where authors are identified as personnel of the International Agency for Research on Cancer/World Health Organization, the authors alone are 
responsible for the views expressed in this article and they do not necessarily represent the decisions, policy of views of these organizations.

\section{Authors' contributions}

PB performed data analysis and drafted the manuscript. VM, IdSS, and JS directed the overall analysis. AA, MG, AZ, GP, and LP coordinated the study at their respective study sites. TA gave advice for data analysis. All authors contributed to results interpretation, revised the manuscript. All authors read and approved the final manuscript.

\section{Funding}

ABC-DO is supported by the Susan G. Komen for the Cure Foundation (IIR 13264158 to IARC and as part of "Implementing breast cancer care efficiency in Zambia through specialized health provider training and m-health evaluation of patient outcomes"for the Zambian site), the National Institutes of Health, and by IARC. The funder of the study had no role in study design, data collection, data analysis, data interpretation, or writing of the report. The corresponding author had full access to all the data in the study and had final responsibility for the decision to submit for publication.

\section{Availability of data and materials}

All data generated or analysed during this study are included in this published article and its supplementary information files.

\section{Declarations}

\section{Ethics approval and consent to participate}

The study was approved by all local and institutional ethics committees [15]. Participants provided written informed consent or, if illiterate, a fingerprint.

\section{Consent for publication}

Not applicable.

\section{Competing interests}

The authors declare that they have no competing interests.

\section{Author details}

${ }^{1}$ International Agency for Research On Cancer (IARC/WHO), Environment and Lifestyle Epidemiology Branch, Lyon, France. ${ }^{2} \mathrm{FMC}$, Owerri, Nigeria. ${ }^{3} \mathrm{AB}$ May Cancer Centre, Windhoek Central Hospital, Windhoek, Namibia. ${ }^{4}$ College of Health Sciences, Makerere University, Kampala, Uganda. ${ }^{5}$ Department of Obstetrics and Gynaecology, School of Medicine, University of North Carolina, Chapel Hill, NC, USA. ${ }^{6}$ University of Washington, Seattle, WA, USA. ${ }^{7}$ Department of Medical Epidemiology and Biostatistics, Karolinska Institutet, Stockholm, Sweden. ${ }^{8}$ World Health Organization, Geneva, Switzerland. ${ }^{9}$ London School of Hygiene and Tropical Medicine (LSHTM), London, UK.

\section{Received: 3 August 2021 Accepted: 9 November 2021}

Published online: 24 November 2021

\section{References}

1. Sung H, Ferlay J, Siegel RL, et al. Global cancer statistics 2020: GLOBOCAN estimates of incidence and mortality worldwide for 36 cancers in 185 countries. CA Cancer J Clin. 2021. https://doi.org/10.3322/caac.21660.

2. McLaughlin SA, Brunelle CL, Taghian A. Breast cancer-related lymphedema: Risk factors, screening, management, and the impact of locoregional treatment. J Clin Oncol. 2020;38:2341-50. https://doi.org/10. 1200/JCO.19.02896.

3. Togawa K, Ma H, Sullivan-Halley J, et al. Risk factors for self-reported arm lymphedema among female breast cancer survivors: a prospective cohort study. Breast Cancer Res. 2014;16:414. https://doi.org/10.1186/ s13058-014-0414-x

4. Kramer N, Ramjith J, Shamley D. Prevalence of shoulder morbidity after treatment for breast cancer in South Africa. Support Care Cancer. 2019;27:2591-8. https://doi.org/10.1007/s00520-018-4540-3.

5. Nesvold IL, Reinertsen KV, Fosså SD, Dahl AA. The relation between arm/shoulder problems and quality of life in breast cancer survivors: a cross-sectional and longitudinal study. J Cancer Surviv. 2011;5:62-72. https://doi.org/10.1007/s11764-010-0156-4.

6. Torgbenu E, Luckett T, Buhagiar MA, et al. Prevalence and incidence of cancer related lymphedema in low and middle-income countries: a systematic review and meta-analysis. BMC Cancer. 2020;20:1-20.

7. Elumelu-Kupoluyi TN, Adenipekun AA, Ntekim Al. Pain associated with secondary lymphedema among cancer patients. J Palliat Care. 2013;29:253-7. https://doi.org/10.1177/082585971302900409.

8. Abass MO, Gismalla MDA, Alsheikh AA, Elhassan MMA. Axillary lymph node dissection for breast cancer: efficacy and complication in developing countries. J Glob Oncol. 2018. https://doi.org/10.1200/JGO.18.00080.

9. Nzeangung BA, Biwole ME, Kadia BM, et al. Evolutionary aspects of non-metastatic breast cancer after primary treatment in a sub-Saharan African setting: a 16-year retrospective review at the Douala general hospital, Cameroon. BMC Cancer. 2018. https://doi.org/10.1186/ s12885-017-3984-z.

10. Sekyere MO, Basson P, Uys C, Armer JM. Incidence of and risk factors for arm lymphoedema following breast cancer treatment: a study in Ghana. J Lymphoedema. 2019;14:41-5.

11. McKenzie F, Zietsman A, Galukande M, et al. Breast cancer awareness in the sub-Saharan African ABC-DO cohort: African Breast Cancer-Disparities in Outcomes study. Cancer Causes Control. 2018;29:721-30. https://doi. org/10.1007/s10552-018-1047-7.

12. McKenzie F, Zietsman A, Galukande M, et al. Drivers of advanced stage at breast cancer diagnosis in the multicountry African breast cancer-disparities in outcomes (ABC-DO) study. Int J Cancer. 2018;142:1568-79. https:// doi.org/10.1002/ijc.31187.

13. Khan F, Charles A, Giwa B, et al. Lymphedema in a patient with stage IV breast cancer due to lymphatic filariasis diagnosed by fine needle aspiration of an axillary lymph node. Am J Clin Pathol. 2016. https://doi.org/10. 1093/ajcp/aqw165.009.

14. Foerster M, Anderson BO, McKenzie F, et al. Inequities in breast cancer treatment in sub-Saharan Africa: findings from a prospective multi-country observational study. Breast Cancer Res. 2019;21:1-11. https://doi.org/ 10.1186/s13058-019-1174-4.

15. McKenzie F, Zietsman A, Galukande M, et al. African Breast Cancer-Disparities in Outcomes (ABC-DO): protocol of a multicountry mobile health prospective study of breast cancer survival in sub-Saharan Africa. BMJ Open. 2016;6:e011390. https://doi.org/10.1136/bmjopen-2016-011390.

16. Foerster M, Anele A, Adisa C, et al. Few losses to follow-up in a SubSaharan African cancer cohort via active mobile health follow-up. Am J Epidemiol. 2020;189:1185-96. https://doi.org/10.1093/aje/kwaa070.

17. Sprangers MA, Groenvold M, Arraras Jl, et al. The European Organization for Research and Treatment of Cancer breast cancer-specific quality-oflife questionnaire module: first results from a three-country field study. J Clin Oncol. 1996;14:2756-68. https://doi.org/10.1200/JCO.1996.14.10. 2756.

18. Hopwood P, Haviland JS, Sumo G, et al. Comparison of patient-reported breast, arm, and shoulder symptoms and body image after radiotherapy for early breast cancer: 5-year follow-up in the randomised Standardisation of Breast Radiotherapy (START) trials. Lancet Oncol. 2010;11:231-40. https://doi.org/10.1016/S1470-2045(09)70382-1.

19. Young-Afat DA, Gregorowitsch $\mathrm{ML}$, van den $\mathrm{DH}$, et al. Breast edema following breast-conserving surgery and radiotherapy: patient-reported prevalence, determinants, and effect on health-related quality of life. JNCl Cancer Spectrum. 2019. https://doi.org/10.1093/jncics/pkz011.

20. Jann B. Stata Tip 8: splitting time-span records with categorical timevarying covariates. Stata J Promot Commun Stat Stata. 2004;4:221-2. https://doi.org/10.1177/1536867×0400400212.

21. Jammallo LS, Miller CL, Singer M, et al. Impact of body mass index and weight fluctuation on lymphedema risk in patients treated for breast cancer. Breast Cancer Res Treat. 2013;142:59-67. https://doi.org/10.1007/ s10549-013-2715-7.

22. Foerster M, McKenzie F, Zietsman A, et al. Dissecting the journey to breast cancer diagnosis in sub-Saharan Africa: findings from the multicountry ABC-DO cohort study. Int J Cancer. 2021;148:340-51. https://doi.org/10. 1002/ijc.33209.

23. Togawa K, Anderson BO, Foerster M, et al. Geospatial barriers to healthcare access for breast cancer diagnosis in sub-Saharan African settings: the African Breast Cancer-Disparities in outcomes cohort study. Int J Cancer. 2021;148:2212-26. https://doi.org/10.1002/ijc.33400. 
24. Honarvar B, Sayar N, Tahmasebi S, et al. Correlates of lymphedema in women with breast cancer: a case control study in Shiraz, Southern Iran Asian Pac J Cancer Prev. 2016;17:81-5. https://doi.org/10.7314/APJCP. 2016.17.S3.81.

25. Hudson M, Connor TO (2021) NCCN harmonized guidelines ${ }^{T M}$ for SubSaharan Africa: Survivorship

26. Hidding JT, Beurskens CHG, Van Der Wees PJ, et al. Treatment related impairments in arm and shoulder in patients with breast cancer: a systematic review. PLoS ONE. 2014;9:e96748.

27. Shamley D, Srinaganathan R, Oskrochi R, et al. Three-dimensional scapulothoracic motion following treatment for breast cancer. Breast Cancer Res Treat. 2009;1 18:315-22. https://doi.org/10.1007/s10549-008-0240-x.

28. Krag DN, Anderson SJ, Julian TB, et al. Sentinel-lymph-node resection compared with conventional axillary-lymph-node dissection in clinically node-negative patients with breast cancer: overall survival findings from the NSABP B-32 randomised phase 3 trial. Lancet Oncol. 2010;11:927-33. https://doi.org/10.1016/S1470-2045(10)70207-2.

29. Nesvold IL, Dahl AA, Løkkevik E, et al. Arm and shoulder morbidity in breast cancer patients after breast-conserving therapy versus mastectomy. Acta Oncol (Madr). 2008;47:835-42. https://doi.org/10.1080/02841 860801961257.

30. Svensson BJ, Dylke ES, Ward LC, et al. Screening for breast cancer-related lymphoedema: self-assessment of symptoms and signs. Support Care Cancer. 2020;28:3073-80. https://doi.org/10.1007/s00520-019-05083-7.

31. Boyages J, Kalfa S, Xu Y, et al. Worse and worse off: the impact of lymphedema on work and career after breast cancer. Springerplus. 2016. https://doi.org/10.1186/s40064-016-2300-8.

32. Shih YCT, Xu Y, Cormier JN, et al. Incidence, treatment costs, and complications of lymphedema after breast cancer among women of working age: a 2-year follow-up study. J Clin Oncol. 2009;27:2007-14. https://doi. org/10.1200/JCO.2008.18.3517.

33. De Vrieze T, Nevelsteen I, Thomis S, et al. What are the economic burden and costs associated with the treatment of breast cancer-related lymphoedema? A systematic review Support Care Cancer. 2020;28:439-49.

34. Cardoso F, Bese N, Distelhorst SR, et al. Supportive care during treatment for breast cancer: Resource allocations in low- and middle-income countries: a Breast Health Global Initiative 2013 consensus statement. Breast. 2013;22:593-605.

35. Distelhorst SR, Cleary JF, Ganz PA, et al. Optimisation of the continuum of supportive and palliative care for patients with breast cancer in lowincome and middle-income countries: executive summary of the Breast Health Global Initiative, 2014. Lancet Oncol. 2015;16:e137-47. https://doi. org/10.1016/S1470-2045(14)70457-7.

36. World Health Organisation (2021) New global breast cancer initiative highlights renewed commitment to improve survival. In: World Health Organisation. https://www.who.int/news/item/08-03-2021-new-globalbreast-cancer-initiative-highlights-renewed-commitment-to-improvesurvival. Accessed 6 Oct 2021

37. O'Brien KS, Soliman AS, Annan K, et al. Traditional herbalists and cancer management in Kumasi, Ghana. J Cancer Educ. 2012;27:573-9.

\section{Publisher's Note}

Springer Nature remains neutral with regard to jurisdictional claims in published maps and institutional affiliations.
Ready to submit your research? Choose BMC and benefit from:

- fast, convenient online submission

- thorough peer review by experienced researchers in your field

- rapid publication on acceptance

- support for research data, including large and complex data types

- gold Open Access which fosters wider collaboration and increased citations

- maximum visibility for your research: over 100M website views per year

At BMC, research is always in progress.

Learn more biomedcentral.com/submissions 